US Army Corps of Engineers ${ }_{\circledast}$

\title{
A Rapid Spectrophotometric Screening Method for 2,4-dinitroanisole in Laboratory Water
}

by Christopher D. Lounds, Alan J. Kennedy, Aimee R. Poda, and Amber L. Russell

PURPOSE: High performance liquid chromatography (HPLC) and gas chromatography (GC) are most commonly used for the measurement of the insensitive munition constituent 2,4 dinitroanisole (DNAN). These methods require investments in equipment, supplies, labor, and training. A screening method was investigated and validated as a low-cost alternative for ecotoxicology testing to quickly quantify DNAN in solution using commonly available instrumentation. This new method uses a spectrophotometer, measuring absorbance in the ultraviolet range. Simple standard curves are employed to determine concentrations of DNAN. Consistently accurate concentrations were validated by HPLC and GC methods. Additionally, the presence of DNAN breakdown products can be observed.

INTRODUCTION: Insensitive munitions containing the constituent 2,4-dinitroanisole (DNAN) are being pursued as safer, more stable alternatives to traditional munitions such as trinitrotoluene (TNT) (Boddu et al. 2009; Kennedy et al. 2013). Current methods for quantifying DNAN in solution require high performance liquid chromatography (HPLC) or gas chromatography (GC). Although these techniques are effective, a reliable, higher throughput, lower-cost, and more accessible screening detection method was desired for ecotoxicology testing. Such a method would benefit laboratory toxicological assessments, which require stock concentration validation, verification of serial dilution concentrations, and a means to rapidly assess compound stability over time.

A screening method was developed to fit these needs using a commonly available spectrophotometer to measure absorbance in the ultra violet range. Concentrations were calculated from absorbance measurements using a standard curve validated by HPLC and GC methods. Further, the development of shoulder peaks in the characteristic DNAN UV-Vis spectra provides information on degradation products (e.g., dinitrophenol, DNP), that are more toxic than DNAN, and may be of aesthetic concern in production waste waters due to the fact that the degradation products have yellow coloration (Koutsospyros et al 2012; Kennedy et al 2013).

MATERIAL AND METHODS: DNAN was acquired from Holston Army Ammunition Plant (BAE Systems, Kingsport, TN, USA; POC: Bob Winstead). Solutions were prepared using ultrapure water (Milli-Q, Plus ultrapure water system, $18.2 \mathrm{~m} \Omega / \mathrm{cm}$, Billerica, MA) or moderately hard reconstituted water (MHRW), formulated as in USEPA (2002). The MHRW is used in toxicological bioassays to simulate surface freshwater (Kennedy et al. 2013). The DNAN stock solutions were prepared using two methods of dissolution; both involved the addition of $25 \mathrm{mg}$ DNAN to $1 \mathrm{~L}(1.26 \mathrm{E}-4 \mathrm{~mol} / \mathrm{L})$ of either MHRW or ultrapure water in a glass volumetric flask. The first dissolution method involved bath sonication (Bransonic, 8510R-DTH, 250W, 
Danbury, CT) for 45 minutes, while the second dissolution method involved magnetic stirring using TFE-coated stir bars in the dark for 48 hours. Wavescans were also performed using small amounts of $25 \mathrm{mg} / \mathrm{L}$ DNP (5\% by volume) added to magnetically stirred DNAN solutions to simulate the presence of breakdown products and associated effect on peak characteristics.

A Cary 5000 UV-Vis spectrophotometer (Agilent, Santa Clara, California) connected to a PC using Agilent Cary WinUV software was used to measure absorbance values at varying DNAN concentrations. Concentration increments were developed by serially diluting $25 \mathrm{mg} / \mathrm{L}$ (1.26E-4 $\mathrm{mol} / \mathrm{L}$ ) nominal stock solution in $50 \%$ increments to achieve five dilutions with nominal concentrations of $25,12.5,6.3,3.1$, and $1.6 \mathrm{mg} / \mathrm{L}$ (1.26E-4, 6.31E-5, 3.18E-5, 1.56E-5, 8.08E-6 $\mathrm{mol} / \mathrm{L})$. Two $\mathrm{ml}$ of DNAN solution was placed in quartz cuvettes $(1 \mathrm{~cm}$ light path length) that were transparent to both ultraviolet and visible wavelengths. Spectra ranging from $200 \mathrm{~nm}$ to $800 \mathrm{~nm}$ were collected and absorbance values at $\lambda-300 \mathrm{~nm}$ were compared against concentration to produce a standard calibration curve. Concentrations were confirmed by HPLC (EPA Method 8330, RDL = $0.02 \mathrm{mg} / \mathrm{L}$ ) and GC (DLS SOP 801.0; Agilent 6890 GC/ECD; U.S. Army Institute of Public Health; POC: David Morrow) methods. Linear regression was applied to these data to produce a standard curve. Kinetic measurements were taken to determine the stability of the DNAN solution. These were performed using the kinetics application within the Cary WinUV software. Application parameters were set to measure absorbance of a $2 \mathrm{ml}$ sample at 2-hour intervals for 24 hours. The samples remained in the dark at room temperature throughout the kinetics analysis.

RESULTS AND DISCUSSION: The spectra of all DNAN stock solutions showed a dominant peak at $300 \mathrm{~nm}$, with a smaller peak at $260 \mathrm{~nm}$ (Figure 1). The DNAN solutions in both MHRW and ultrapure water prepared using sonication resulted in slight yellowing of the solution, whereas the magnetically stirred method produced colorless solutions. This color change occurred in both water sources and may indicate the presence of numerous breakdown products, such as 2,4-dinitrophenol, which is known to be produced from DNAN by alkaline hydrolysis (Hill et al. 2012; Koutsospyros et al. 2012).

Since DNP was identified as a potential breakdown product (Hill et al. 2012; Koutsospyros et al. 2012), a comparison of spectra was performed at various concentrations of DNP to examine peak positioning and peak magnitudes relative to DNAN. The resulting spectra (Figures 1,2) for DNP produced peaks at $360 \mathrm{~nm}$ with slightly higher absorbance values than those seen at equivalent concentrations of DNAN (0.78 absorbance units for DNP compared to 0.70 for DNAN at nominal concentrations of $12.5 \mathrm{mgL}$, or $6.31 \mathrm{E}-5 \mathrm{~mol} / \mathrm{L}$ ). The peak positioning was consistent between samples using the stirring method of DNAN preparation. For sonicated solutions, consistent peak shape and magnitude of the peak positioned at $300 \mathrm{~nm}$ were difficult to reproduce. This inconsistency may indicate degradation of the DNAN in solution as supported by the resulting color change.

The magnetically stirred DNAN solutions produced consistent peak magnitudes at $300 \mathrm{~nm}$, indicating no significant levels of breakdown products, as confirmed by extensive analytical chemistry in Kennedy et al. (2013). This method of preparation showed no change in peak characteristics over the 24-hour kinetics scan (Figure 2). The magnetically stirred DNAN samples with added DNP reproduced similar color intensity as seen in sonicated samples. The addition of DNP at $1 \% \mathrm{v} / \mathrm{v}$ showed no apparent effect on peak shape, whereas the $5 \% \mathrm{v} / \mathrm{v}$ addition produced a peak shoulder in the $360 \mathrm{~nm}$ range. 


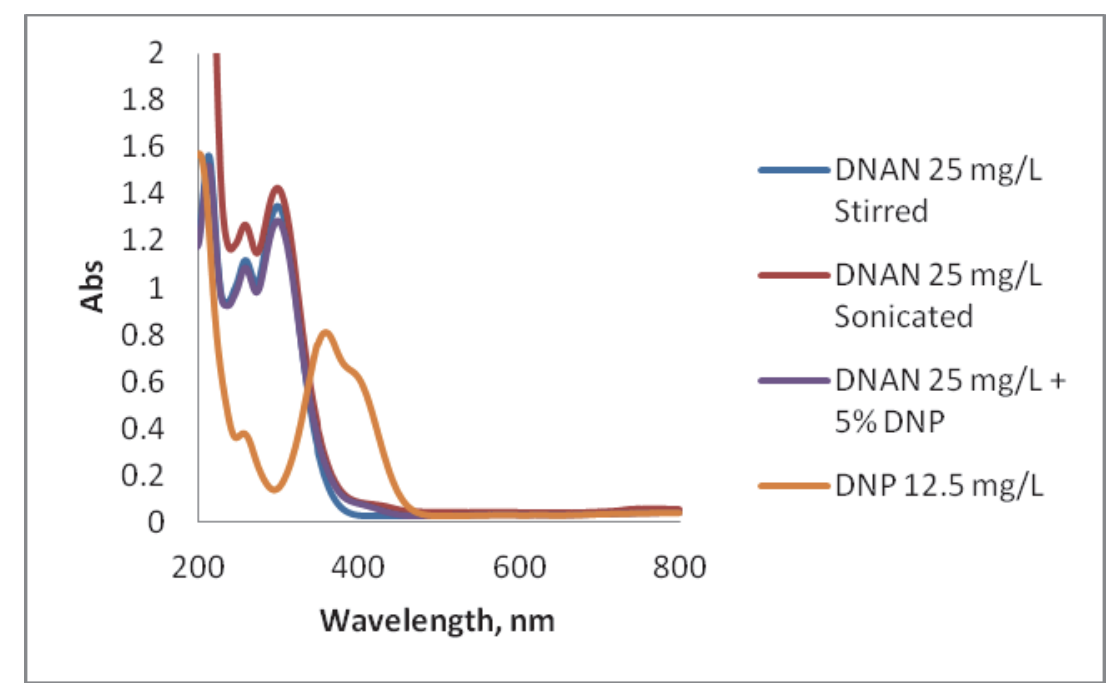

Figure 1. DNAN and DNP wavescans from $200 \mathrm{~nm}$ to $800 \mathrm{~nm}$.

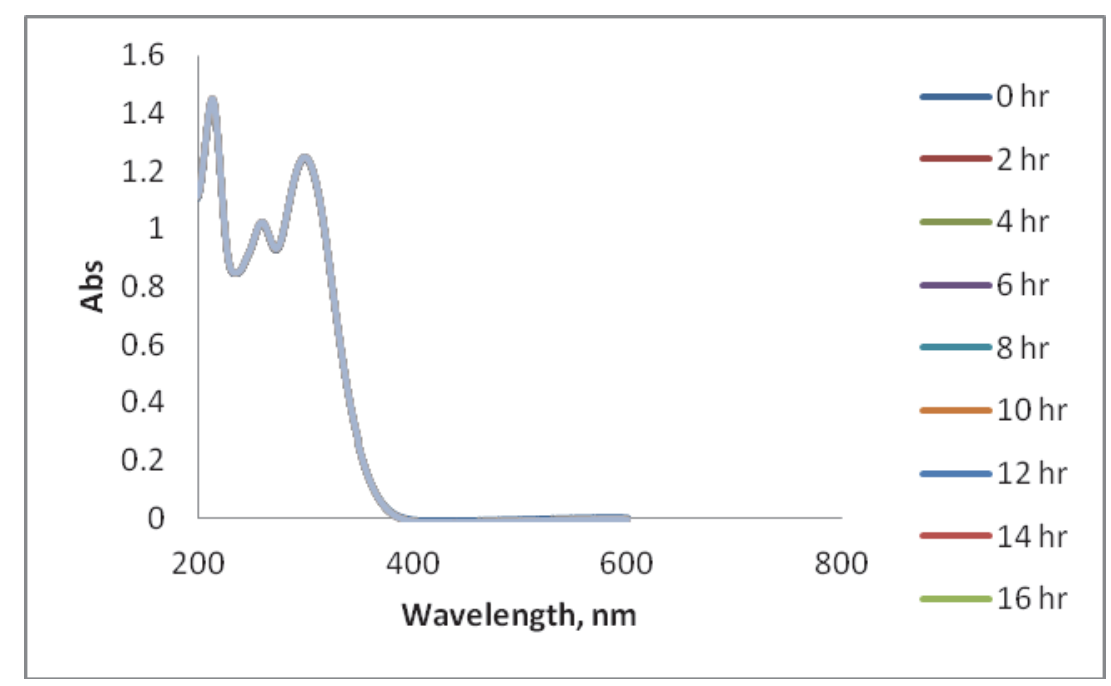

Figure 2. DNAN kinetics wavescan over a 24-hour period indicating no change in peak shape or magnitude.

Magnetic stirring was determined to be the more consistent method for use in future toxicological testing. The source of water (ultrapure vs. MHRW) showed no effect on the peak location or magnitude. A series of low-concentration DNAN dilutions were measured with the spectrophotometer to find the detection limit of the method. The lowest concentration of DNAN that produced consistently accurate results was $0.024 \mathrm{mg} / \mathrm{L}$ (or $1.21 \mathrm{E}-7 \mathrm{~mol} / \mathrm{L}$ ). Alternatively, the method detection limit of absorbance measurement with the spectrophotometer was determined at $0.20 \mathrm{mg} / \mathrm{L}$ (or $1 \mathrm{E}-6 \mathrm{~mol} / \mathrm{L}$ ), based on the y-intercept. The absorbance of the DNAN samples was plotted against the concentrations measured by HPLC to produce a standard curve (Figure 3) with an extinction coefficient of $0.0001 \mathrm{M}^{-1} \mathrm{~cm}^{-1}(\lambda=300 \mathrm{~nm})$ that can be applied to simple waters containing DNAN for rapid concentration determinations.

CONCLUSION: A new rapid screening method of measuring the concentrations of DNAN in laboratory water was developed to return fast and reliable values at a low cost. Using a standard 
spectrophotometer and simple calculations, this method was capable of producing accurate measurements as an alternative to standard, longer turnaround analytical techniques. The low cost and ease of use associated with spectrophotometer equipment is well suited for applications such as quick screening or for laboratories that do not have extensive analytical capabilities.

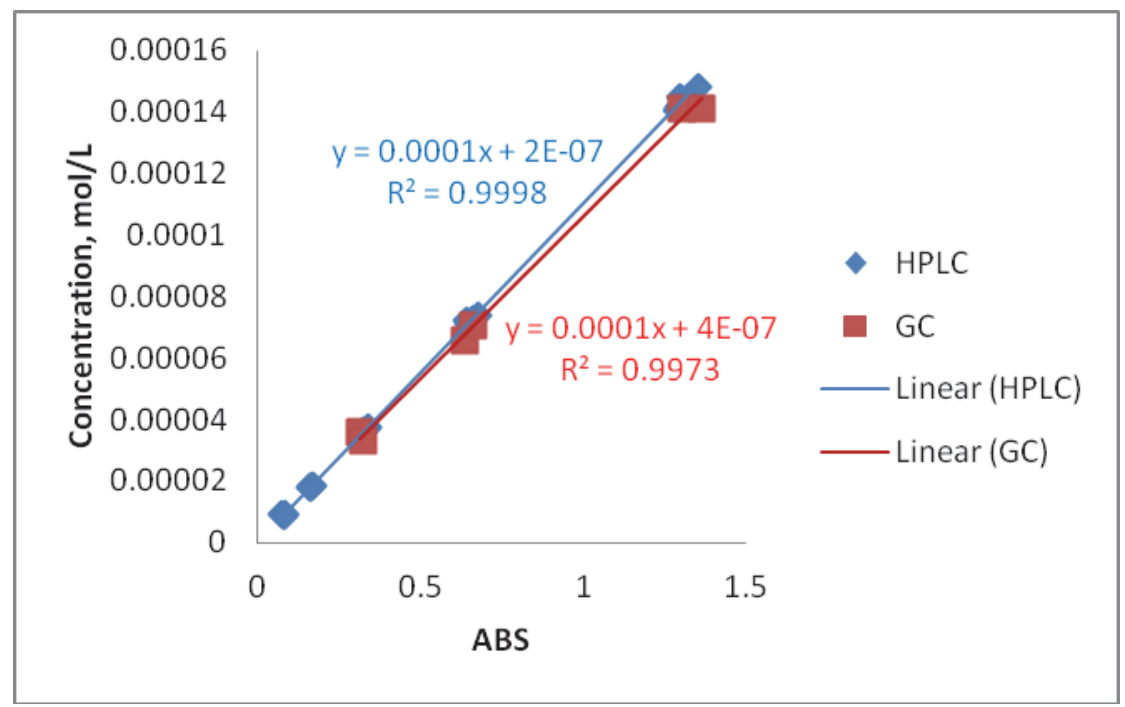

Figure 3. DNAN standard curve plot of absorbance (ABS) against HPLC and GC measured concentration (on the y-axis).

ACKNOWLEDGEMENTS: This work was funded by the Army Environmental Quality Technology Basic Research Program (U.S. Army Engineer Research and Development Center, Martin Savoie and Dr. Elizabeth Ferguson, Technical Directors). Permission was granted by the Chief of Engineers to publish this information.

POINTS OF CONTACT: For additional information, contact Alan J. Kennedy (601-634-3344, alan.j.kennedy@usace.army.mil).

This technical note should be cited as follows:

Lounds, C. D., A. J. Kennedy, A. R. Poda, and A. L. Russell. 2014. A rapid spectrophotometric screening method for 2,4-dinitroanisole in laboratory water. Technical Notes Collection. ERDC/EL TN-14-3. Vicksburg, MS: U.S. Army Engineer Research and Development Center.

\section{REFERENCES}

Boddu, V. M., K. Abburi, A. J. Fredricksen, S. W. Maloney, R. Damavarapu. 2009. Equilibrium and column adsoprtion studies of 2,4-dinitroanisole (DNAN) on surface modified granular activated carbons. Environ. Technol. 30: 173-181.

Hill, F. C., L. K. Sviatenko, L. Gorb, S. I. Okovytyy, G. S. Blaustein, J. Leszczynski, 2012. DFT M06-2X investigation of alkaline hydrolysis of nitroaromatic compounds. Chemosphere 88: 635-643. 
Kennedy, A. J., C. D. Lounds, N. L. Melby, J. G. Laird,B. Winstead, S. M. Brasfield, M. S. Johnson. 2013. Development of environmental health criteria for insensitive munitions: Aquatic ecotoxicological exposures using 2,4-Dinitroanisole. ERDC/EL TR-13-2. Vicksburg, MS: U.S. Army Engineer Research and Development Center. http://el.erdc.usace.army.mil/elpubs/pdf/trell3-2.pdf

Koutsospyros, A., J. Pavlov, J. Fawcett, D. Strickland, B. Smolinski, W. Braida, 2012. Degradation of high energetic and insensitive munitions compounds by $\mathrm{Fe} / \mathrm{Cu}$ bimetal reduction. J. Haz. Mat. 219-220: 75-81.

U.S. Environmental Protection Agency (USEPA). 2002. Methods for measuring the acute toxicity of effluents and receiving waters to freshwater and marine organisms, 4th ed. EPA-821-R-02-012. Washington, DC: Office of Water, USEPA.

NOTE: The contents of this technical note are not to be used for advertising, publication, or promotional purposes. Citation of trade names does not constitute an official endorsement or approval of the use of such products. 